\title{
BAGAIMANA MENENTUKAN SLIP PADA TRANSMISI PULLEY \& V-BELT PADA BEBAN TERTENTU DENGAN MENGGUNAKAN MOTOR BERDAYA SEPEREMPAT HP
}

\author{
Syafrizal \\ Program StudiTeknikMesin \\ Politeknik Enjinering Indorama \\ Email: saf_89@yahoo.com
}

\begin{abstract}
ABSTRAK
Tidak banyak para teknisi menggunakan transmisi putaran pada mesin dari satu poros keporos yang lain memperhitungkan adanya slip antara poros dengan transmisi, sehingga putaran ouput poros yang diharapkan tidak tercapai. Seperti yang ditunjukkan pada transmisi pulley dan v-belt, pada pulley dan $v$ belt bahwa putaran output yang disampaikan pada pulley akan terjadi penurunan nilai putaran beberapa persen karena timbul slip antara belt dengan pulley. Penurunan nilai putaran tersebut akan bertambah dengan bertambahnya massa putaran yang dibawa. Dalam penelitian ini menggunakan motor $1 / 4 \mathrm{Hp}$ dan putaran $1410 \mathrm{rpm}$, pulley dan $v$-belt dengan koefisien gesek sebesar $\mu=0,3$. Secara analisa teoritis dengan memilih factor kritis 1,056 maka nilai putaran tersebut akan berubah sebesar 1489 mpm, dengan rasio putaran pulley sebesar $\mathrm{i}=2,953216$. Ketika dilakukan pengujian dengan beban massa $1,707 \mathrm{~kg}$ maka putaran poros motor diperoleh sebesar $1489 \mathrm{rpm}$, dengan menggunakan rasio putaran maka putaran pulley output sebesar 504,2 rpm, tetapi pada pengukuran putaran pulley sebesar 497,35 rpm, sehingga menimbulkan selisih sebesar 6,9 rpm atau mengalami slip sebesar 1,39\%, dan nilai ini akan terus bertambah dengan bertambahnya beban massa putar yang dibawa. Berdasarkan analisa empiris besarnya slip dengan menggunakan program excel, maka didapatlah persamaan hubungan persentase slip dengan perubahan massa yang dipakaiseperti; $\%, 5 p=18,713 \ln (n \pi)=11,441$.
\end{abstract}

Kata kunci: motor, pulley,v-belt.

\section{ABSTRACT}

Not many engineers use a round on the engine transmission from one shaft to another shaft that takes into account the existence of slippage between the spindle with the transmission, so the rotation axis of the expected output is not reached. As shown in the transmission and the v-belt pulley, the pulley and $v$-belt that round of output delivered on the pulley will be impaired rounds a few percent for signage slip between the belt with the pulley. Impairment round is going to increase with increasing mass brought round. In this study, using the motor rounds $1 / 4 \mathrm{hp}$ and $1410 \mathrm{rpm}$, and v-belt pulley with a friction coefficient of $\mu=0.3$. By theoretical analysis to select the critical factor 1.056, the value of the round will be unchanged at $1489 \mathrm{rpm}$, with pulley rotation ratio of $i=2.953216$. When tested with a load of 1,707 $\mathrm{kg}$, the mass of the motor shaft rotation obtained at $1489 \mathrm{rpm}$, using the rotation pulley rotation ratio amounted to $504.2 \mathrm{rpm}$ output, but the pulley rotation measurement of $497.35 \mathrm{rpm}$, resulting in a difference of $6.9 \mathrm{rpm}$ or a slip of $1.39 \%$, and this value will continue to grow with the increasing burden of the play brought the masses. Based on empirical analysis of the amount of slip using excel program, then the equation didapatlah slip percentage relationship with mass changes that were used like; \% Slip $=13.715 \ln (m)-11.441$.

Keywords: motor, pulley, v-belt

\section{PENDAHULUAN}

Banyak sekali pemakaian pulley dan v-belt yang digunakan sebagai alat transmisi pada mesin mesin konvensional, maupun mesin yang moderen, namun tidak jarang penggunaan pulley dan $v$-belt tanpa memperhitungkan faktor slip yang timbul antara pulley dan v-belt sehingga putaran yang diharapkan tidak muncul.

Berkenaan dengan masalah diatas maka dilakukanlah pengujian dan penelitian pada transmisi pulley dan $v$-belt dengan menggunakan motor berdaya $1 / 4 \mathrm{Hp}$ sebagai sumber penggerak.

Besarnya slip yang terjadi pada putaran pulley dan $v$-belt akan di analisa secara teori dan praktis yang menggunakan alat ukur putaran (tachometer). 
Diketahuinya besar slip antara pulley dan v-belt maka kita dapat menetukan berapa besar nilai beban yang harus diberikan untuk suatu daya dan putaran pada spesifikasi motor, sehingga kebutuhan daya dan putaran dapat disesuaikan dengan besarnya nilai beban yang harus diberikan.

\section{METODOLOGI PENELITIAN}

Dalam pencapaian hasil penelitian yang berjudul "Bagaimana Menentukan Slip Pada Transmisi Pulley\& V- Belt Pada Beban Tertentu Dengan Menggunakan Motor Berdaya 1/4 Hp”, maka dilakukan tahapan yang dimulai dengan suatu pembuatan alat uji, menguji, melakuk ananalisa hasil uji secara teoritis dan praktis, serta pembuatan laporan hasil analisa.

Analisa permasalahan menggunakan pengalaman lapangan, konsultasi dengan beberapa pihak dan menggunakan referensi buku-buku keteknikkan yang mendukung. Mesin uji dan alat uji yang digunakan dapat dilihat pada gambar 1, sebagai berikut:

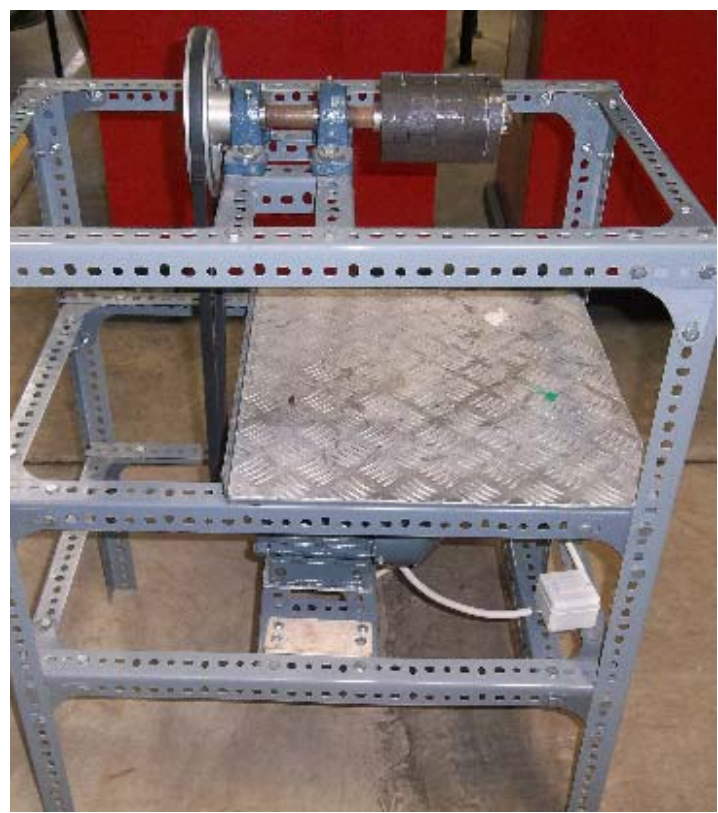

(a) tampak samping

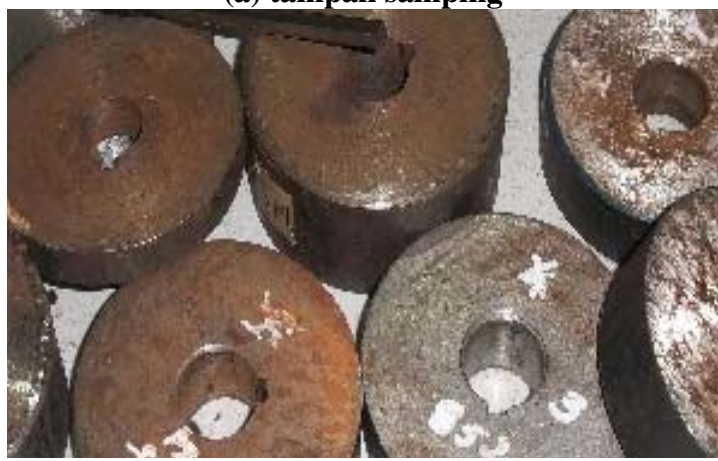

(c) benda uji

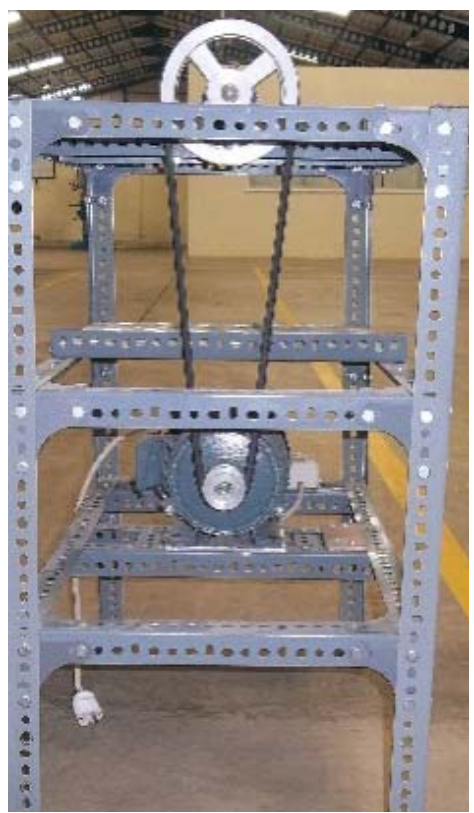

(b) tampak depan

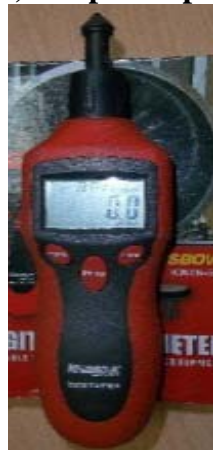

(d) tachometer

Gambar 1. Mesin uji yang digunakan, benda uji dan alat ukur putaran poros

\section{HASIL DAN PEMBAHASAN}

Untuk mendapatkan hasil yang dicapai maka perlu ada dua jenis kajian yang dikemukakan baik secara teorits maupun secara praktis dengan data yang aktual, sebagai berikut: 


\subsection{Analisa Teoritis}

Spesifikasi data alat yang digunakan:

a. Pulley dengan rasio (i) $=2,953216$

b. Daya motor $=1 / 4 \mathrm{Hp} \approx 186,5$ watt

c. Putaran motor $(\mathrm{n})=1410 \mathrm{rpm}$

d. diameter poros $=19,5 \mathrm{~mm}$

e. pulley dan v-belt ${ }^{[1]}$, ditampilkan dalam tabel 1, sebagai berikut:

Tabel 1. Spesifikasi pulley yang digunakan[1][5]

\begin{tabular}{lll}
\hline No & Nama & Nilai \\
\hline 1 & Pulley kecil $\left(\mathrm{d}_{1}\right)$ & $51,3 \mathrm{~mm}$ \\
2 & Pulley esar $\left(\mathrm{d}_{2}\right)$ & $151,5 \mathrm{~mm}$ \\
3 & Lebar belt $(\mathrm{w})$ & $12,5 \mathrm{~mm}$ \\
4 & Masa jenis belt(karet): $\mathrm{Q}$ & $1.14 \mathrm{~kg} / \mathrm{cm}^{3}$ \\
5 & Tebal belt $(\mathrm{t})$ & $9 \mathrm{~mm}$ \\
6 & Suduttekan $(2 \beta)$ & $40^{\circ}$ \\
7 & Koefisiengesek $(\mu)$ & 0,3 \\
8 & Jarakporos pulley $(\mathrm{C}=\mathrm{X})$ & $445 \mathrm{~mm}$ \\
\hline
\end{tabular}

f. Panjang belt dapat dihitung dengan persamaan 1[1],sebagai berikut:

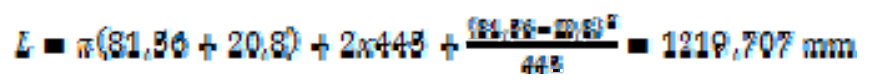

g. Putaran motor yang sebenarnya dapat dihitung dengan persamaan 2[4], sebagai berikut:

$$
\left(\mathrm{n}_{1}\right)=\mathrm{f}_{\mathrm{c}} \times \mathrm{n}
$$

dengan:

o Faktor koreksi $\left(\mathrm{f}_{\mathrm{c}}\right)=1,056$

o Putaran motor (n) $=1410 \mathrm{rpm}$

Maka Putaran motor sebenarnya adalah:

$\mathrm{n}_{1}=\mathrm{f}_{\mathrm{c}} \mathrm{x} \mathrm{n}=1,020 \times 1410=1489$ mpm

h. Putaran pulley yang digerakkan dapat dihitung dengan persamaan 3[1][4], sebagai berikut:

$$
n_{5}=\frac{15}{i}
$$

Putaran pulley output berdasarkan rasio putaran yang dimiliki, maka:

\section{$m_{\mathrm{g}}=\frac{m_{\mathrm{k}}}{t}=\frac{1480,8}{2,88216}=301,31 \mathrm{mp} \mathrm{rpm}$}

Selanjutnya analisa putaran pulley penggerak dan yang digerakkanakan ditampilkan dalam suatu table hasil pada tabel 2.

\subsection{Analisa Praktis}

Nilai hasil secara praktis dan secara aktual didapat dari hasil putaran pulley yang diukur secara langsung menggunakan tachometer, seperti yang ditampilkan pada tabel 2 dan gambar 2 sebagai berikut: 
Tabel 2. Hasil uji putaran motor dan pulley

\begin{tabular}{ccccc}
\hline \multirow{2}{*}{ No } & \multirow{2}{*}{$\begin{array}{c}\text { Massa } \\
(\mathbf{K g})\end{array}$} & $\begin{array}{c}\text { Putaran } \\
\text { motor }\end{array}$ & \multicolumn{2}{c}{$\begin{array}{c}\text { Putaran Pulley Aktual }(\boldsymbol{A}) \boldsymbol{d} \\
\text { Teoritis }(\boldsymbol{T})\end{array}$} \\
\cline { 3 - 5 } & & motor $(\boldsymbol{r p m})$ & $\boldsymbol{A}(\boldsymbol{r p m})$ & $\boldsymbol{T}(\boldsymbol{r p m})$ \\
\hline 1 & 1,707 & 1489,150 & 497,350 & 504,2 \\
2 & 2,534 & 1488,283 & 497,000 & 504,0 \\
3 & 3,41 & 1486,933 & 496,300 & 503,5 \\
4 & 3,875 & 1486,000 & 496,200 & 503,2 \\
5 & 3,542 & 1483,000 & 493,163 & 502,2 \\
6 & 4,768 & 1482,000 & 433,413 & 501,8 \\
7 & 6,503 & 1480,000 & 420,000 & 501,1 \\
8 & 7,774 & 1465,000 & 400,000 & 496,1 \\
\hline
\end{tabular}

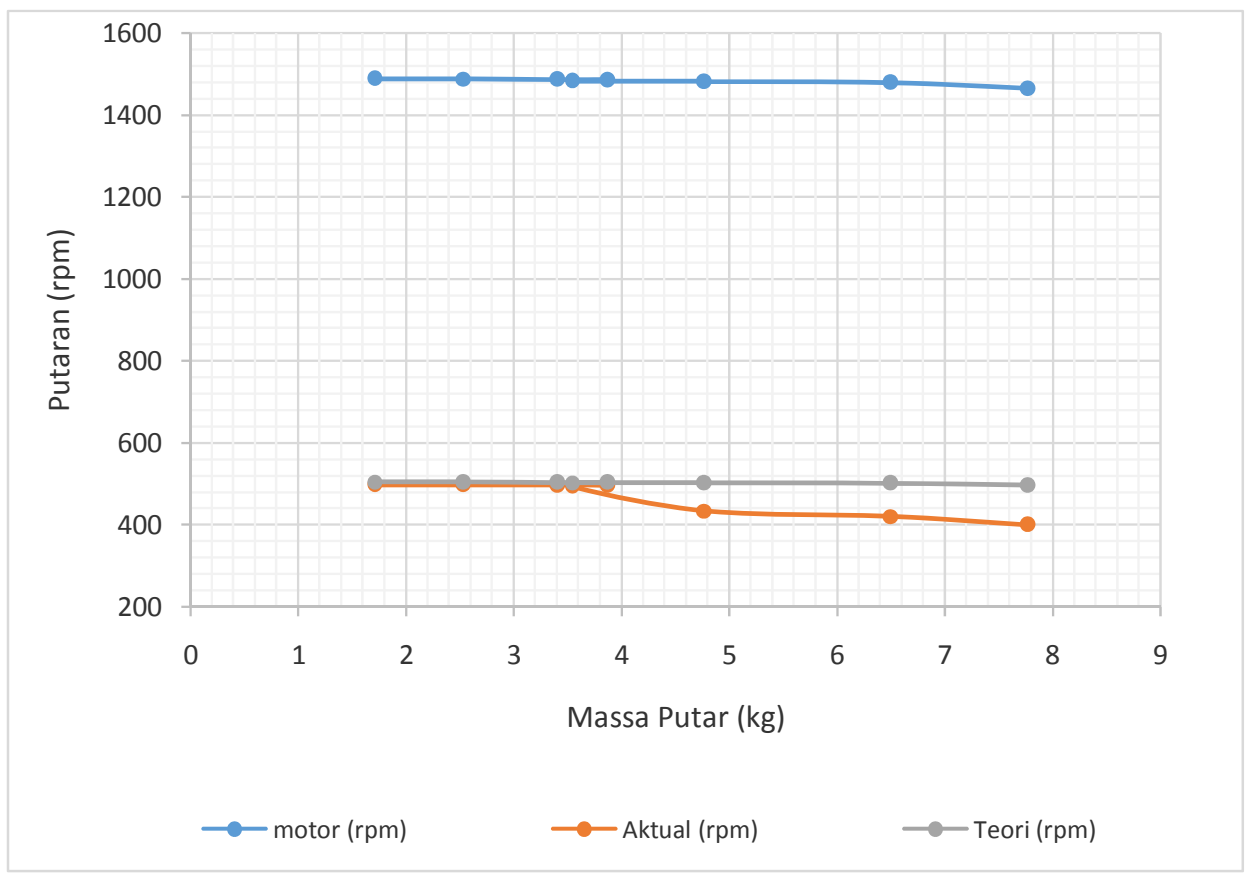

Gambar 2. Grafis hasil pengukuran putaran aktual (A) dan teoritis (T)

Slip antara pulley dan belt dapat dihitung pada persamaan 4[2][3], sebagai berikut:

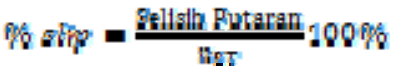

Untuk $n_{2 F}=504,26 \mathrm{rpm}$ dan $n_{2,}=497,4 \mathrm{rpm}$, maka persentase slip yang terjadi adalah:

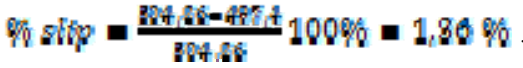

Perhitungan putaran output pulley selalu didasar pada nilai pemberian beban dalam satuan $\mathrm{kg}$. Perhitungan putaran pulley secara teoritis atau actual dihitung berdasarkan putaran motor yang didapat dari pembacaan tachometer, kemudian secara teoritis akan dihitung dengan nilai rasio putaran, dan secara actual akan dihitung langsung dengan pembacaan tachometer, seperti yang ditampilkan pada tabel 3 . Untuk melihat hasil perhitungan persentase slip antara pulley dan beltjuga dapat dilihat pada gambar 3 . 
Tabel 3. Hasil perhitungan koefisien gesek, \% slip putaran(rpm)

\begin{tabular}{ccccccc}
\hline & \multicolumn{7}{c}{$\begin{array}{c}\text { Putaran } \\
\text { No }\end{array}$} & $\begin{array}{c}\text { massa } \\
(\mathbf{K g})\end{array}$ & \begin{tabular}{c} 
motor \\
\cline { 3 - 5 }
\end{tabular} & $\begin{array}{c}\text { motor } \\
\text { aktual \& }\end{array}$ & $\boldsymbol{A}(\mathbf{r p m})$ & $\boldsymbol{T}(\mathbf{r p m})$ & $\boldsymbol{A})$ & \\
& & $(\mathbf{r p m})$ & & & & \\
\hline 1 & 1,707 & 1489,150 & 497,350 & 504,2 & 6,90 & 1,39 \\
2 & 2,534 & 1488,283 & 497,000 & 504,0 & 6,95 & 1,40 \\
3 & 3,41 & 1486,933 & 496,300 & 503,5 & 7,20 & 1,45 \\
4 & 3,875 & 1486,000 & 496,200 & 503,2 & 6,98 & 1,41 \\
5 & 3,542 & 1483,000 & 493,163 & 502,2 & 9,00 & 1,83 \\
6 & 4,768 & 1482,000 & 433,413 & 501,8 & 68,41 & 15,78 \\
7 & 6,503 & 1480,000 & 420,000 & 501,1 & 81,15 & 19,32 \\
8 & 7,774 & 1465,000 & 400,000 & 496,1 & 96,07 & 24,02 \\
\hline
\end{tabular}

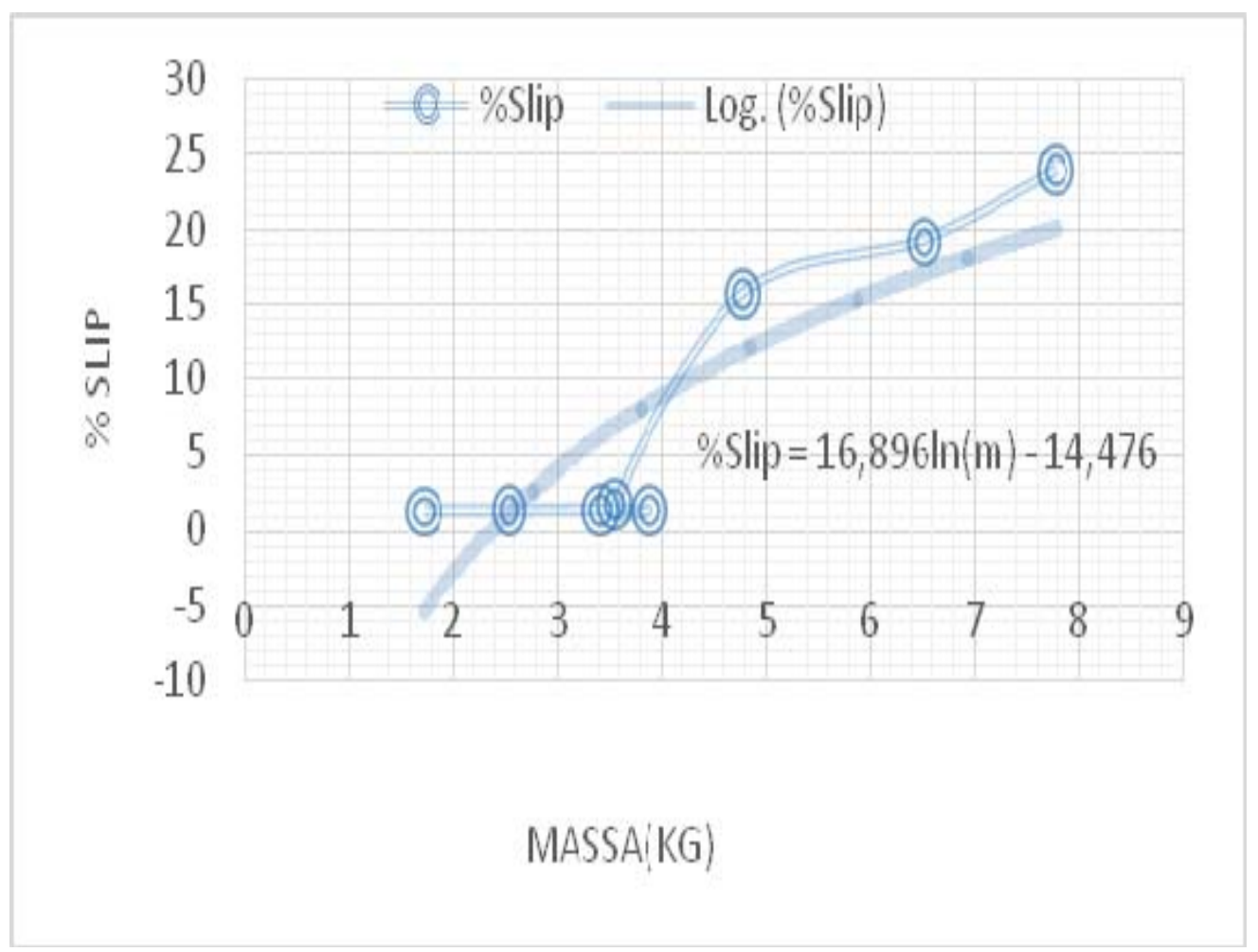

Gambar 3. Perubahan \% slip terhadap perubahan massa putar

\section{KESIMPULAN}

Hasil pengujian terhadap perubahan kecepatan output motor dengan menggunakan transmisi pulley dan $v$-belt, di dapat suatu persamaan $\%$ slip $=16,986 \ln (\mathrm{m})-14,476$. Dimana \%Slip sebanding dengan peningkatan nilai beban pada mesin. 


\section{DAFTAR PUSTAKA}

[1] R.S.Khurmi,J.K.Gupta, 2005. Text book of machine design S.I. Units. New Delhi : Eurasia Publishing House (Pvt) LTD.

[2] Ferdinand L Singer, Pytel Andrew, Darwin Sebayang. 1995. Ilmu Kekuatan Bahan (Terjemahan). Penerbit: Erlangga, Jakarta.

[3] Nash A. William, 1983. Strength of Materials Second Edition: McGraw-Hill International Book Company, Singapura

[4] Sularso, Kiyokatsu suga, 2008, Dasar Perencanaan dan Pemilihan Elemen Mesin: Pt. Pratnya Paramita.

[5] Rudianto Raharjo, 2013. Rancang Bangun Belt Conveyor Trainer Sebagai Alat Bantu Pembelajaran. Jurnal Teknik Mesin, Politeknik Kediri., vol 4, No2. ISSN 2252-4444. 